\title{
Research on a Dynamic Truck Scale Weighing System for Container
}

\author{
Mingwang Dong ${ }^{1, a}$, Feifei Zhu ${ }^{1, b}$, Wenyi $\mathrm{Yu}^{1, \mathrm{c}}$ \\ ${ }^{1}$ School of Logistics Engineering, Wuhan University of Technology, \\ Wuhan, Hubei, 430063, China \\ adongmingwang2002@163.com,b673278392@qq.com,,15271843937@163.com
}

Keywords: dynamic truck scale; two containers in series connection; signal processing.

\begin{abstract}
At present, the domestic weighing technology applications focus on overload weighing of road vehicles, and there is great research space in port containers' weighing. In view of the situation that container trucks queue a long line for truck weighing before entering the harbor, the paper studies dynamic truck weighing system. Through setting up suitable experimental platform and post-processing algorithm, it has designed the overall experimental programs. Particularly considering specific vehicle's models and the case of two containers in series connection, it designed the layout of the experimental weighing platform.
\end{abstract}

\section{Introduction}

Container transportation occupies a very large proportion in port logistics. With the continuous boost of the globalization of logistics, more and more goods are transported in the way of container transport. However, in ocean transportation, the uneven distribution of container shipping stowage brought serious consequences. So, container weighing technology has been researched at home and abroad. The popular three weighing method of many container ports are as follows ${ }^{[1]}$. The first one is that containers were respectively weighed by dedicated hanging equipment. The second one is getting peeled weight through the formular of the whole weight of vehicle minus the tare weight in the way of static weighing, and reducing the error by gravity modified formula. The third one is dynamic truck scale weighing system for container. Those low and high frequency signal will be cut down through subsequent professional algorithm .The static weighing has the highest accuracy of the above methods, which can make the container weight anastomose its gravity, but it will likely cause congestion in port's entrance. Dedicated scales is working in the stock dump, and it is extremely accurate However, it may delay the execution and formulation of storage yard project and finally reduce productive efficiency in harbor port. Compared with the other two ways, dynamic container weighing can not only speed up weighing velocity which will solve the crowded situation in harbor port, but also give a convenience to draw up a plan of storage yard and shipment in advance ${ }^{[2]}$. Therefore, this way is the direction of the study on modern container weighing system.

In this paper, the whole project about weighing system is designed specially in dynamic truck weighing system. Considering the situation of single container and double containers in series connection, the important point is the study in double weighing system which includes selection of experimental models, designation of weighing platform, establishment of mechanical model and the weighing signal processing algorithm. In conclusion, it is feasibility to some degree.

\section{Technical Solution of Dynamic Truck Scale System}

An overview of overall solution. The solution of port container dynamic weighing technology mainly concludes hardware scheme and software solutions. Hardware scheme studies these aspects including the selection of container truck model and experimental design of the weighing platform in order to complete arrangement of experiment site. Software solutions in-depth study the weighing signal processing algorithms, and also try to find out the compensation algorithm. Compared with 
dynamic weighing in highway mouth, port containers' weighing is convenient for stack and to ensure the safety of the ship stowage. So, the weighing accuracy is comparatively reduced.

The scheme adopts three axes load measurement point to weigh the container truck in hardware. Vehicles with a certain speed pass above three weighing platforms with different length arranged in a certain order. Each weighing platform weighs three axles for a little period and has three weighing curves on front, middle and back axle load of the vehicle. Through taking effective information by algorithm, the real axle load of each axis can be gotten. According to the two situations of vehicle loading single container and double containers, the weight of each container is computed at last ${ }^{[3]}$.

In single container's situation, because of models fixed, the Single container weight is equal to total weight of the three axles' load minus the weight of the empty vehicle. In double container's situation, mechanical model should be established to calculate the weight of each container, and the biases of container's center of gravity can be modified through compensation algorithm. The plan is mainly to design and research the specific plan about double containers' situation. The concrete content is as follows:

(1)Through the collection of model data and the choice of the weighing platform, it builds the experimental hardware platform to research some common models of double 20 feet container ${ }^{\text {[4] }}$. It extends three static measurement point weighing technology to the dynamic truck scale. On the basis of the model structure of container trailer, mechanics model is set up. Finally, the weight of the front and the back container can be calculated.

(2) In the process of data processing, signal of low frequency and high frequency should be processed respectively. Through the establishment of a new algorithm adapting to the three points' measurement and dynamic weighing, the influence of the external environment factors of vehicle load will be reduced as far as possible, and the static approximation of each axle load will be calculated.

Container standardization transport is not only embodied in container size, but also embodied in container vehicle models. After collecting an enormous container vehicle models, it is not difficult to find that container vehicle type is mainly concludes two kinds, single container and double container. Double container is chosen in this paper .Figure 1 is the model of a typical double container truck, as an object of the research. Table 1 is a data table of container truck models and the size in certain harbor.

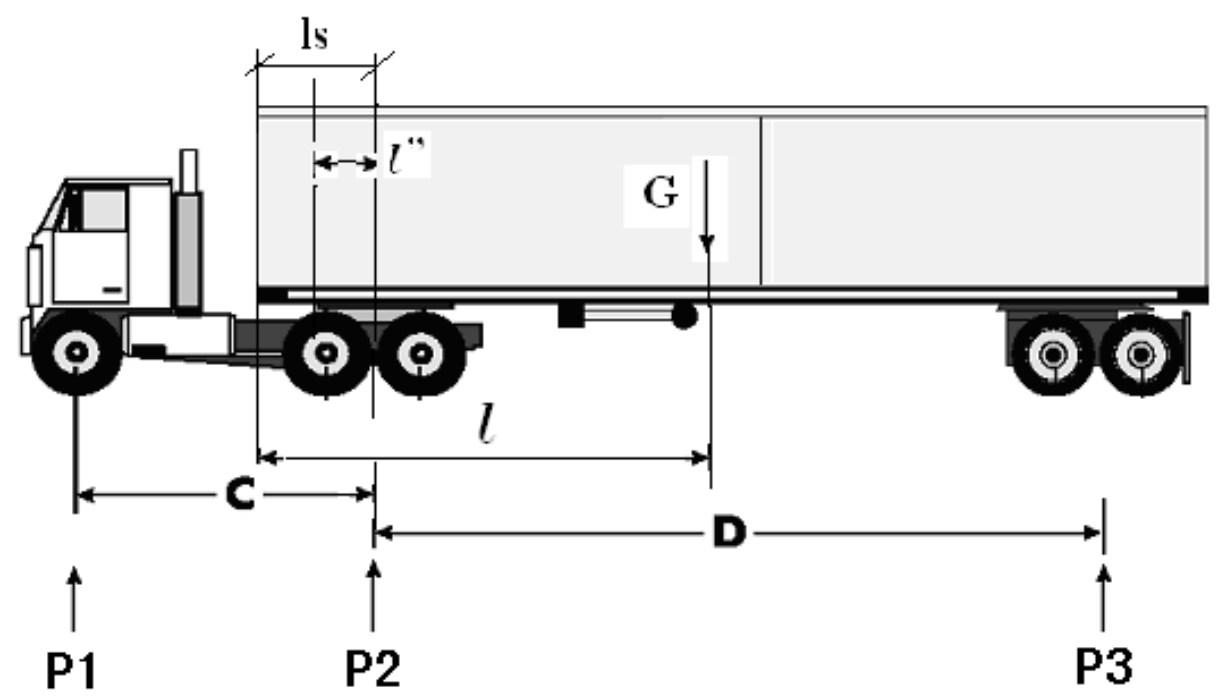

Fig.1 Model of double container truck 
Table 1 Data collection template

\begin{tabular}{|c|c|c|c|c|}
\hline Name & $\begin{array}{l}\text { Symbol / } \\
\text { unit }\end{array}$ & Example & $\begin{array}{c}\text { Correspondence software } \\
\text { description }\end{array}$ & Remarks \\
\hline Tractor weight & $\mathrm{g}(\mathrm{kg})$ & 9340 & Tractor weight $(\mathrm{kg})$ & \\
\hline Container trailer weight & $g^{\prime}(\mathrm{kg})$ & 7580 & Trailer weight $(\mathrm{kg})$ & \\
\hline $\begin{array}{l}\text { Distance between the central } \\
\text { pin and a central shaft } \\
\text { l" }\end{array}$ & $\mathrm{mm}$ & 950 & $\begin{array}{l}\text { The pin shaft distance } \\
\text { (mm) }\end{array}$ & \\
\hline $\begin{array}{l}\text { Distance between the central } \\
\text { shaft and the front container } \\
\text { ls }\end{array}$ & $\mathrm{mm}$ & 215 & $\begin{array}{l}\text { The shaft end distance } \\
\text { (mm) }\end{array}$ & \\
\hline $\begin{array}{l}\text { Distance between the front } \\
\text { and the central shaft } \\
\text { C } \\
\end{array}$ & $\mathrm{mm}$ & 5400 & $\begin{array}{c}\text { Front and central shaft } \\
\text { distance } \\
(\mathrm{mm}) \\
\end{array}$ & \\
\hline $\begin{array}{c}\text { Distance between the } \\
\text { central and back shaft } \\
\text { D }\end{array}$ & $\mathrm{mm}$ & 6400 & $\begin{array}{l}\text { Central and back shaft } \\
\text { distance (mm) }\end{array}$ & \\
\hline $\begin{array}{l}\text { Empty weight on front } \\
\text { shaft P1' }\end{array}$ & $\mathrm{kg}$ & 5205 & $\begin{array}{l}\text { Empty weight on } \\
\text { Shaft } 1\end{array}$ & \\
\hline $\begin{array}{c}\text { Empty weight on central shaft } \\
\text { P2' }\end{array}$ & $\mathrm{kg}$ & 6130 & $\begin{array}{l}\text { Empty weight on } \\
\text { Shaft } 2\end{array}$ & \\
\hline $\begin{array}{l}\text { Empty weight on back shaft } \\
\text { P3' }\end{array}$ & $\mathrm{kg}$ & 5585 & $\begin{array}{l}\text { Empty weight on } \\
\text { Shaft } 3\end{array}$ & \\
\hline Empty truck tare & $\mathrm{kg}$ & 16920 & Empty truck's weight & $\begin{array}{l}\text { Automatic calculation(the } \\
\text { sum of three axes ) }\end{array}$ \\
\hline $\begin{array}{l}20 \text { ' The length of the } \\
\text { container }\end{array}$ & $\mathrm{L}^{\prime}(\mathrm{mm})$ & 6000 & & \\
\hline
\end{tabular}

Weighing platform, also known as loadometer, usually contains two types: floor weighing platform and ground weighing platform. The ground weighing platform contains two types of shallow foundation and the piers mode. The cost of floor weighing platform is low, but it is higher than the horizon. So, in order to reduce the influence on weighing accuracy when the vehicle is accelerating in and out the scale, ground pier weighing platform is more applicable in this scheme. Shallow foundation has no drainage system, for which it has high cost for repairing. So, the piers mode is the best model, which is showed in Figure 2.

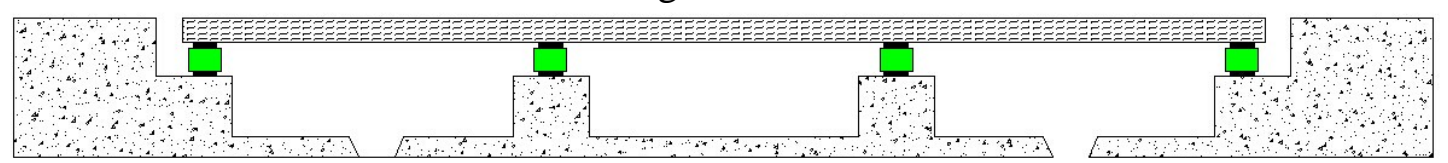

Fig.2 Pier type weighing platform

The main part of the weighing platform is the pier type weighing platform. According to previous vehicle data, the design of weighing platform distribution is as shown in Figure 3.The design scheme, which have three weighing platforms, can provide more data collection points when the truck runs over weighing station at a low speed. The effective interval of weighing platform's data can be read through weighing instrument, and transmission mode is wired transmission which can ensure the real time and accuracy of data. According to the model data in double container case, the length of three scale platforms should be designed respectively as follows: $1.9 \mathrm{~m}, 4.9 \mathrm{~m}$ and $5.9 \mathrm{~m}$. In this way, selecting the length of time when three axes are on the scale at the same time meets the requirements of calculation accuracy. 


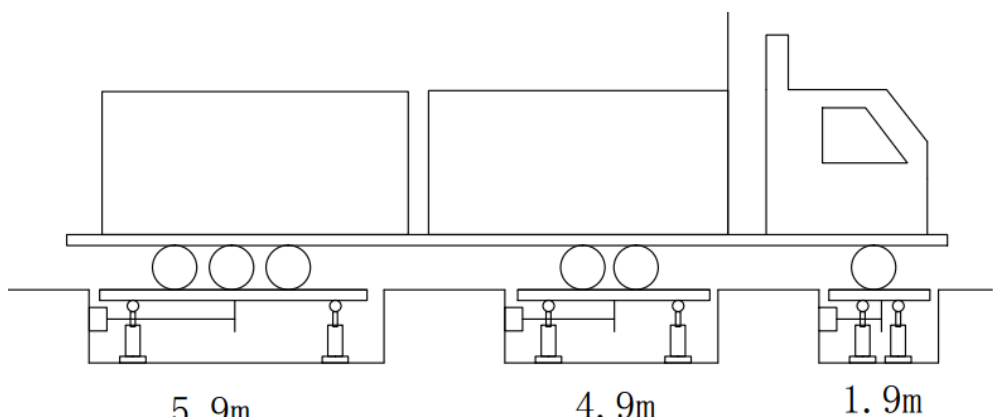

Fig.3 The blueprint of weighing platform distribution

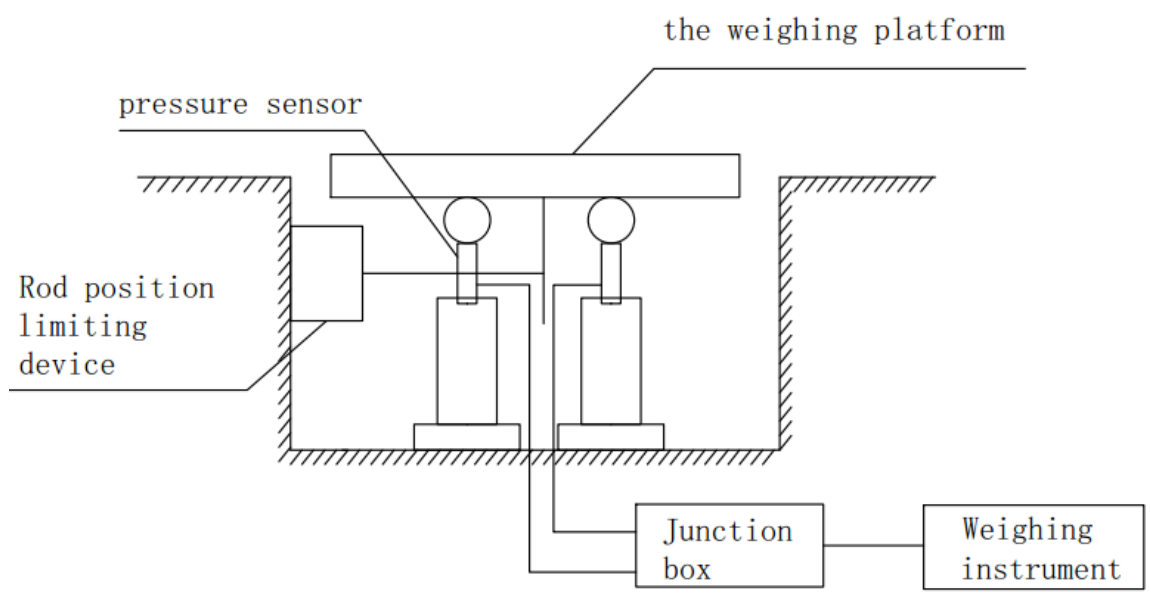

Fig.4 The internal structure of weighing platform

The internal structure of weighing platform is shown in Figure 4, which consists five parts: the weighing platform, pressure sensor, rod position limiting device, junction box and weighing instrument. The working principle of this weighing platform system is as follows. When vehicle passed over three weighing platforms at a constant speed, four weighing sensors detected the pressure of each platform, and then pressure signal is converted into electrical ones through the junction box and transferred to weighing instrument. After that, it is the weighing instrument's work to complete amplifying, filtering, analog digital conversion and other work which are related to weighing electrical signals. Every weighing platform followed the above steps to calculate the axle's weight. Finally, the three axle's weight, after treatment, was transferred to the upper monitor. Through the mechanical model calculation formula that set in computer in advance, the weight of each container can be calculated, and display data can be known on the display screen. Specific process is shown in Figure 5.

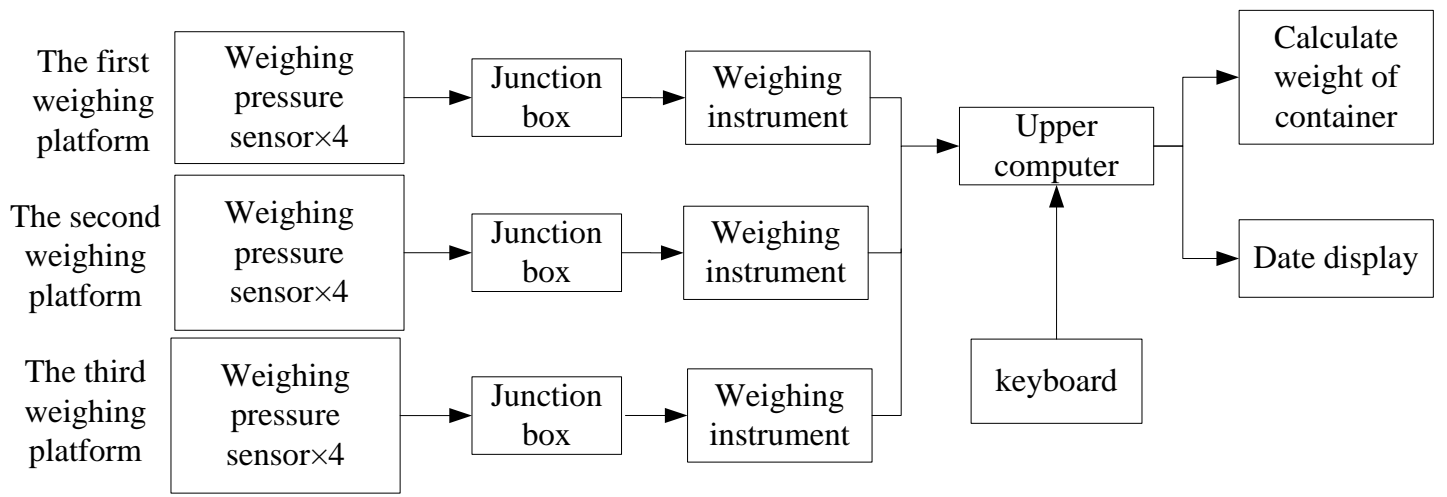

Fig.5 Workflow of dynamic vehicle weighing system

In the case of double container trucks, vehicle's force analysis is shown in Figure 6. 


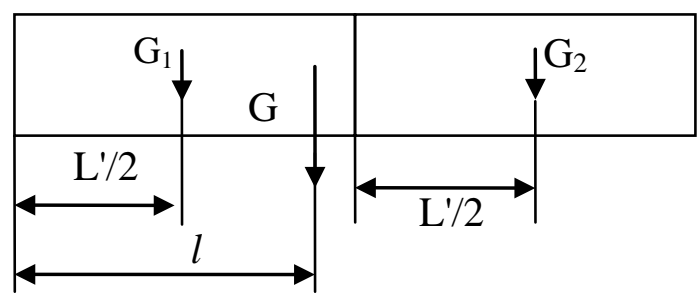

Fig.6 Double container weight distribution map

The meanings of forces in Figure 6 are as follows.

G----Cargo weight (It can be obtained by weighing)

$L^{\prime}$--- 20' The length of the container (known)

$l$---Distance between center of gravity and the front container

By analysing Figure 6 (Double container weight distribution map), the single container weight formula is as follows. (Hypothesis: the goods in single container are uniformly assembled, the core of which is in the central position)

$$
\begin{aligned}
& \left\{\begin{array}{l}
G_{1}=\frac{G\left(3 L^{\prime}-2 l\right)}{2 L^{\prime}} \\
G_{2}=\frac{G\left(2 l-L^{\prime}\right)}{2 L^{\prime}}
\end{array}\right. \\
& l=\frac{\left(P_{3}-P_{3}^{\prime}\right)^{*}\left(D+l^{\prime \prime}\right)}{G}+l s-l^{\prime \prime}
\end{aligned}
$$

Equation 2 is a formula when truck is loaded ( $l$ stands for the distance between center of gravity and the front container ).Put Equation 2 into Equation 1, and the calculation formula of single tank container can be known, which is Equation ${ }^{[5]}$.

$$
\left\{\begin{array}{l}
G_{1}=\frac{G \times\left(3 L^{\prime}-2 l s+2 l^{\prime \prime}\right)-2\left(P_{3}-P_{3}^{\prime}\right) \times\left(D+l^{\prime \prime}\right)}{2 L^{\prime}} \\
G_{2}=\frac{G \times\left(2 l s-2 l^{\prime \prime}-L^{\prime}\right)+2\left(P_{3}-P_{3}^{\prime}\right) \times\left(D+l^{\prime \prime}\right)}{2 L^{\prime}}
\end{array}\right.
$$

Among the elements in Equation 3, $P_{3}$ and $P_{3}^{\prime}$ stand for the third axis pressure respectively in load and unload condition. Through Equation3, it is not difficult to find $P_{3}$ and $P_{3}{ }^{\prime}$ are the display data from the sensor. So, their accuracy is particularly important to the whole system. The above hardware platform and the mechanics model were established to ensure the normal operation of field experiment, and all the work laid a foundation for the next step of weighing signal processing.

Weighing signal processing.This scheme adopts the above measurement scheme to get continuous signal of three weighing platforms. It is the most accurate to select the signal period when three axes load respectively on the three scales. However, it is a short time when vehicle running at high speed above the weighing platform .So, how to collect enough amount of signal in such a short time for subsequent processing is the key point of the system. Weighing system itself also are susceptible to interference, such as electrical signal interference, weather conditions and delayed signal transmission, which will also impact on data acquisition. This kind of interference mainly is caused by the circuit within the system and vehicle's electronic equipment, which belongs to the high frequency signal. In addition, the vehicle's factors (engine rotation, tire friction with the ground, auto gears, brakes, steering, uneven fuel combustion etc.), road uneven and some other factors will cause the vehicle vibration, which eventually form a dynamic load. The amplitude of dynamic load can 
reach more than $10 \%$ of the real vehicle axle load, generally within $30 \mathrm{HZ}$ frequency. Only by digital filtering method cannot eliminate the influence of the dynamic load of dynamic weighing. This kind of the interference is caused by low frequency signal.

Signal processing method of high frequency and low frequency is different. The high frequency signal is processed through wavelet denoising method to obtain a pure signal. The wavelet analysis method is more suitable for non-stationary signal processing. Through decomposition of the signal layers, high frequency noise is extracted. The effective waveform part can reflect the local characteristics of time domain and frequency domain ${ }^{[6]}$. The Fourier decomposition method can only reflect the local characteristics of frequency domain, and have no resolution in time domain. In the software MATLAB, the wavelet transform is a method with high frequent uses, but the selection standard of wavelet function is complex, which will be discussed and solved in subsequent research.

Low frequency signal processing methods, such as integral method, compensation method and the parameter estimation method, are not adopted by this scheme, because the weighing accuracy using above methods is not very high. Empirical mode analysis (EMD) can increase the accuracy of low frequency signal processing. The vehicle's axle load signal consists of automobile static axle load and dynamic load. So, it is correct to regard vehicle static axle load as the residual amount of signal(reaction trend of average or average amount of steady state) and the dynamic load as the intrinsic mode function of the signal. At last, dynamic load was isolated from the vehicle axle load signal by using the method EMD, and eventually the vehicle's static axle load is achieved.

\section{Conclusions}

The program selected the vehicle's model, weighing platform type and number of measurement points, and established proper mechanics model to solve the problem about single container's weight. The program also has set up a preliminary experiment platform to ensure the normal order of the experiment and the output signal waveform. During the data processing phase, signals of low and high frequency were respectively treated to reduce the error of the weighing signal.

Deficiency is that the selection of data processing algorithm remains to be decided, and the experiment of weighing platform has no in-depth research scheme. Hope to make a breakthrough and progress in the further study.

\section{Acknowledgements}

This work was financially supported by the Fundamental Research Funds for the Central Universities (WUT: 2014-IV-146).

\section{References}

[1] LiXun. Research on a New Truck Scale Weighing System for Container and Error Analysis [J]. Port Operation,2009,02:1-4.

[2] M. Niedźwiecki, A. Wasilewski. Application of Adaptive Filtering to Dynamic Weighing of Vehicles[J]. Control Engineering Practice,1996,45.

[3] Karl Wild, Hermann Auernhammer. A Weighing System for Local Yield Monitoring of Forage Crops in Round Balers[J]. Computers and Electronics in Agriculture,1999,232.

[4] LIU Zhong-jie1,HE Feng1,SONG Xiao-bo2. Research of Tandem Container's Weigh-in-motion System for a Single Container [J]. Science Technology and Engineering, 2012,03:590-595+606.

[5] FanHua. Research and Practice on New Type of Dynamic Truck Scale Weighing System [J]. Industrial \& Science Tribune,2014,02:74-75.

[6] ChenNan. The Compensation Algorithm Research and the Software Design of WIM Vehicles System [J]. Science \& Technology Apphcatlon,2009. 